\title{
Follow the Shoestring: A Unique Case of Bullet Extraction
}

Danier Ong ${ }^{1}$, Parth M. Joshi ${ }^{1}$, Holly Zehfus ${ }^{1}$, Timothy Havens ${ }^{1}$

1. Emergency Medicine, Saint Louis University School of Medicine, St. Louis, USA

Corresponding author: Danier Ong, danier.ong@health.slu.edu

\begin{abstract}
Firearm-related injuries and deaths remain a major issue in the United States. Gunshot injuries to the foot can be particularly difficult to manage when they occur as they can cause fractures or devastating neurovascular damage. There are limited reasons for routine bullet removal in most cases. Acute indications include wounds involving joints, palms, and soles as well as increased risk of infection, persistent pain, and lead intoxication. Here, we bring attention to a case of a gunshot wound to the left foot of a 53-year-old male, in which the bullet was able to be extracted using a shoe fiber that had become wrapped around the bullet.
\end{abstract}

Categories: Emergency Medicine, Trauma

Keywords: bullet wound, bullet fragment, bullet extraction, lower extremity trauma, emergency medicine and trauma

\section{Introduction}

According to the 2018 data from the Centers for Disease Control and Prevention (CDC), there were estimated to be 39,740 firearm-related deaths in the United States [1]. In addition, over 67,000 Americans are nonfatally injured by firearms each year [2]. The issue is so prevalent in American society that the CDC notes seven out of every 10 medically treated firearm injuries are the result of a firearm-related assault [1]. The effect that these injuries can have on individuals can range from hospitalization to death. Injuries to the foot are particularly challenging due to anatomical and functional considerations related to that region. A preponderance of gunshot injuries to the foot result in fracture, and there is a higher chance of intraarticular involvement with neurovascular injury [3]. Another unique consideration that must be made when a foot/ankle gunshot injury occurs is whether to retrieve the bullet. This decision is made based on the presence of motor issues, location of the lesion, and degree/exacerbation of pain [3]. The most common types of imaging used to assess gunshot injuries are x-rays and can be escalated to total body CT if there are signs of vascular damage present [4]. Here, we report a case of a gunshot wound to the left foot of a 53-year-old male, in which the bullet was able to be extracted using a shoe fiber that had become wrapped around the bullet.

Review began 04/25/2021 Review ended 05/04/2021 Published 05/05/2021

\section{๑) Copyright 2021}

Ong et al. This is an open access article distributed under the terms of the Creative Commons Attribution License CC-BY 4.0., which permits unrestricted use, distribution, and reproduction in any medium, provided the original author and source are credited.

\section{Case Presentation}

A 53-year-old male without known significant past medical history presented to the emergency department for a gunshot wound to the left foot. He reported leaving a bar when a shot was fired, hitting him in the foot. He noted pain and bleeding but was able to walk. His pain was worsened with palpation to the affected site. The patient denied any significant family history. His social history was significant for tobacco use of two packs per day and alcohol use of six to 12 beers a day.

Upon arrival, blood pressure was 152/85 $\mathrm{mmHg}$, pulse was $76 \mathrm{bpm}$, respiratory rate was $18 \mathrm{bpm}$, the temperature was $97.6^{\circ} \mathrm{F}$, and $\mathrm{O}_{2}$ saturation was $100 \%$ on room air. On examination, there was a wound with associated tenderness and edema to the medial aspect of the left foot with no other findings noted. A left foot $\mathrm{x}$-ray was ordered and tetanus, diphtheria, and pertussis (Tdap) vaccine were administered intramuscularly. X-ray imaging revealed a large bullet fragment in the plantar soft tissue beneath the medial cuneiform as well as punctate fragments in the medial soft tissue near the large fragment. There were no fractures noted on imaging (Figure 1). 


\section{Cureus}

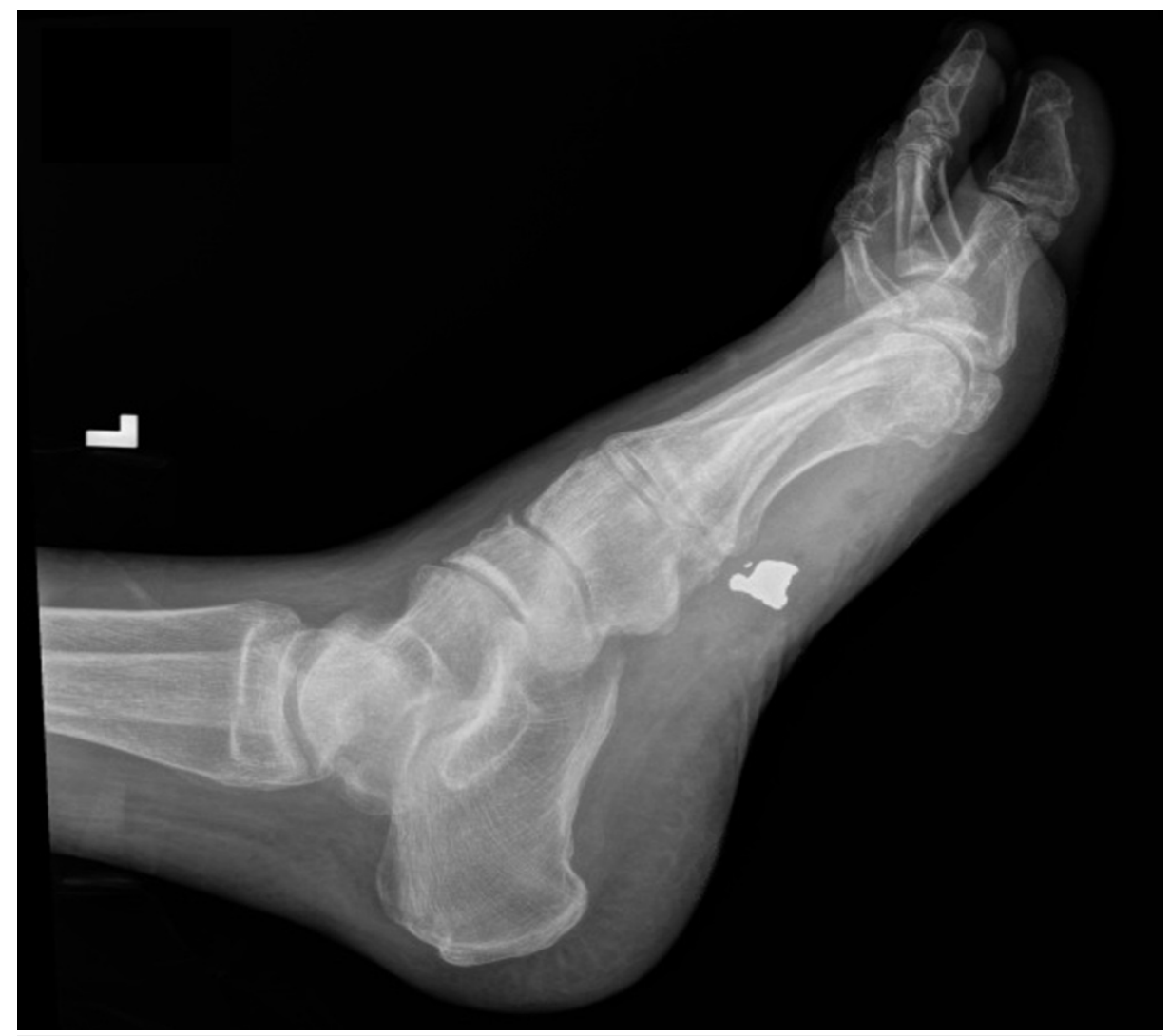

FIGURE 1: X-ray foot left lateral view (before bullet removal)

Lidocaine $1 \%$ with epinephrine was administered locally and removal of the bullet was attempted. The bullet path was tracked by following pieces of thread detached from the patient's shoe, which was found to be wrapped around the bullet (Figure 2). 


\section{Cureus}

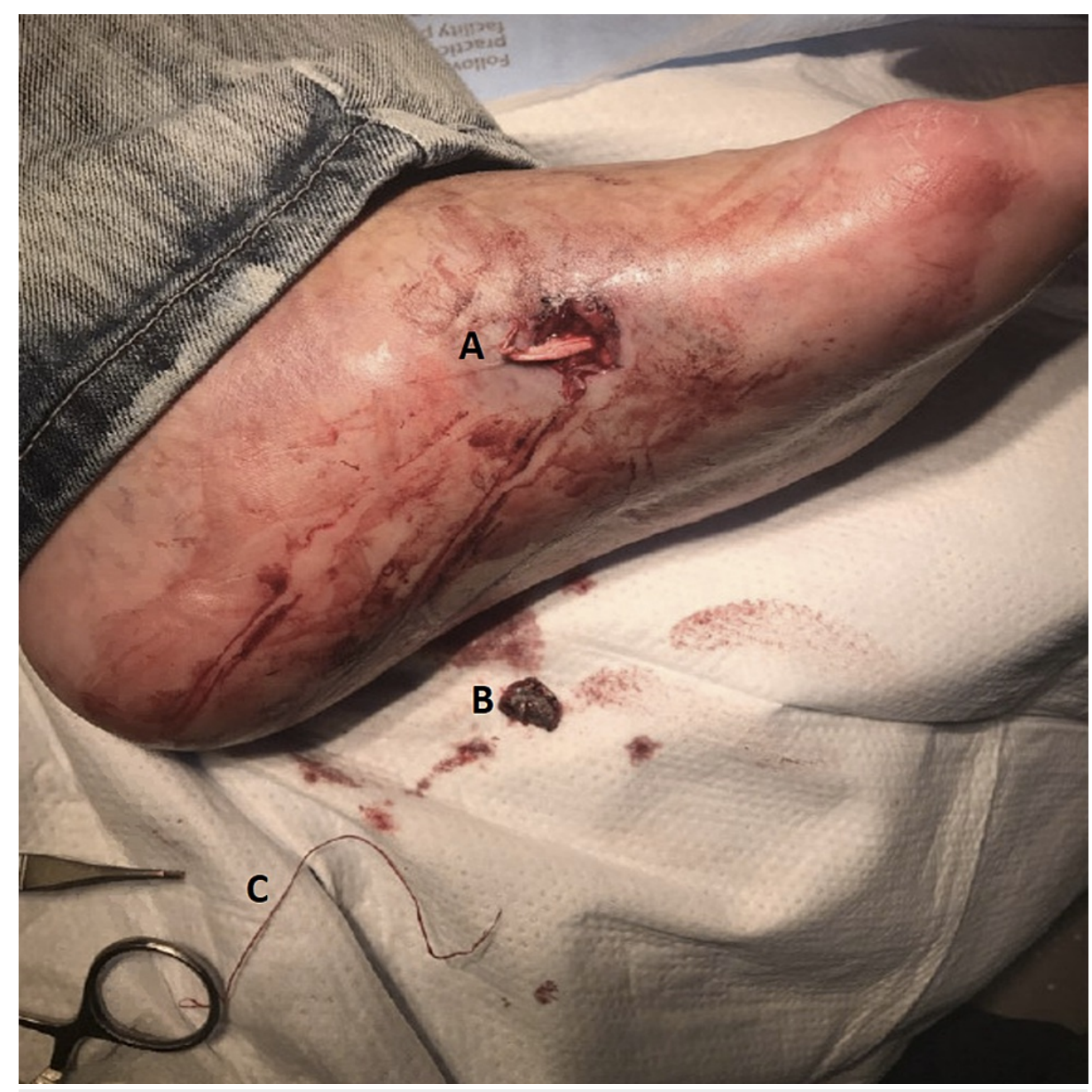

FIGURE 2: Left foot gunshot wound with a removed bullet fragment

A. Gunshot wound

B. Bullet fragment

C. Shoe fiber that had been wrapped around bullet fragment

Bullet extraction was performed by pulling the shoe fibers along the bullet path. The severed tendon was visible upon extraction following bullet removal. Plantar and dorsiflexion of all toes of the left foot were intact. Orthopedic surgery was consulted and recommended a repeat $\mathrm{x}$-ray which showed removal of the large bullet fragment in the plantar soft tissues (Figure 3). 


\section{Cureus}

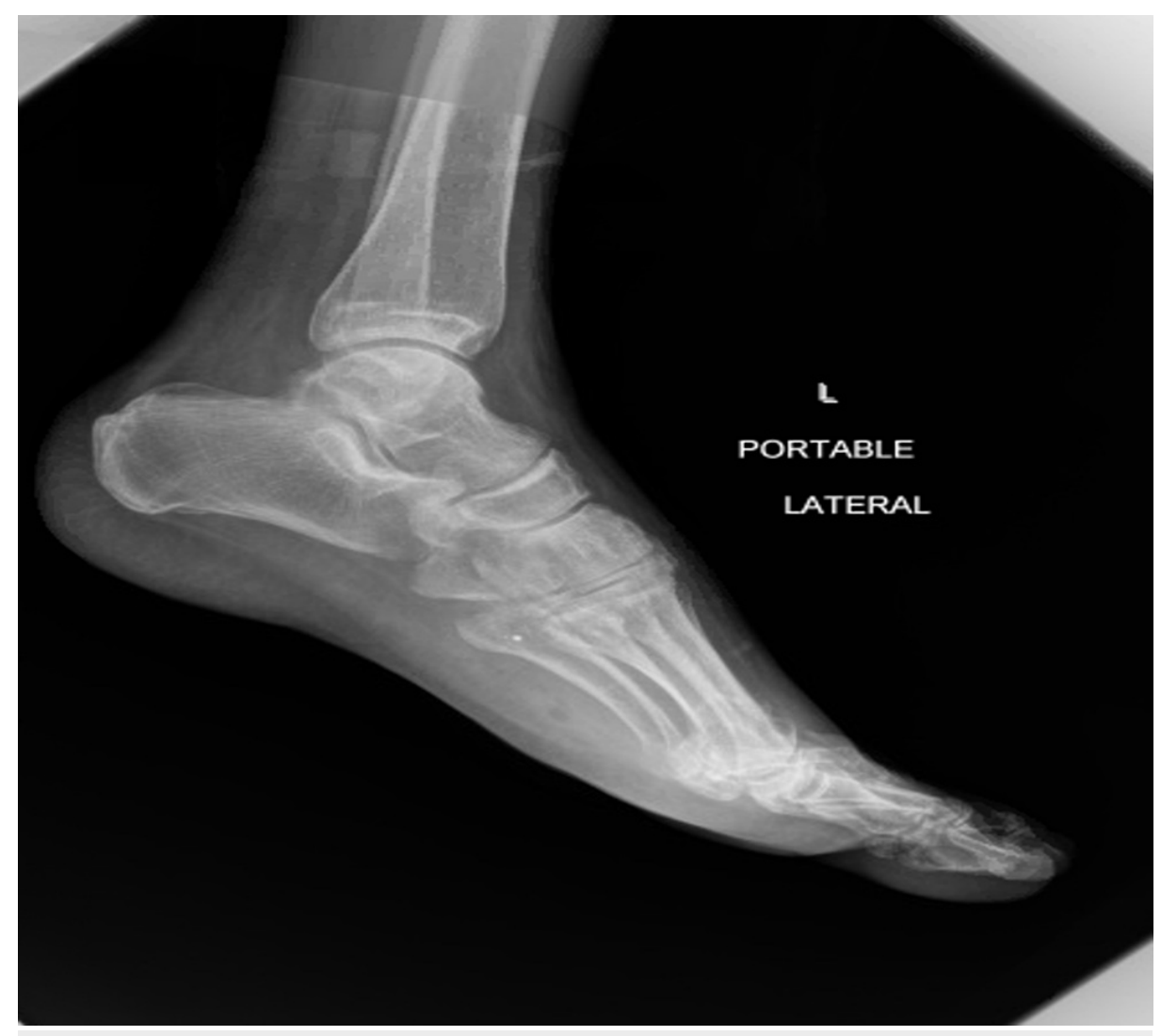

FIGURE 3: X-ray foot left lateral view (after bullet removal)

The patient was discharged with topical bacitracin and ciprofloxacin $500 \mathrm{mg}$ tablet two times daily for seven days. He was provided with crutches and instruction for outpatient management with orthopedic surgery. The patient did not follow up for further management.

\section{Discussion}

A prior systematic review of gunshot wounds and bullet removal has concluded that there is no rationale for routine bullet removal in all cases; acute indications for removal include wounds involving joints, palms, and soles as well as increased risk of infection, persistent pain, and lead intoxication [5]. Upon evaluation of our patient, it was subjectively determined that bullet extraction would be challenging. Removal of bullets within soft tissue is not typically indicated except in specific situations as previously stated. The majority of literature discussing bullet removal from the extremities involves arthroscopy for intra-articular injuries or surgical intervention involving fractures of the foot [6]. In regards to non-complicated soft tissue injures, management typically involves superficial irrigation as opposed to formal surgical irrigation and debridement $[3,7,8]$. The issue we faced was a non-complicated soft tissue injury, specifically affecting the foot. It has been previously noted that gunshot wounds can worsen prognosis due to the increased risk of damaging adjacent neurovascular structures [9]. Considering the proximity of the bullet to plantar vessels and nerves, this patient carried the potential for further injury from bullet migration, exacerbated via repeated movement and ambulation. Additionally, the persistent discomfort exacerbated by palpation and ambulation provided further rationale for the extraction. Based on these determinations, management recommendations were reconsidered.

The decision to manage conservatively versus operatively was facilitated by the presence of the shoe fibers. Typical bullet extraction necessitates further wound incision in a sterile, operative setting, which would have created a greater burden on the patient and his recovery. From this, it can be concluded that removal of the bullet via the shoe fibers prevented further soft-tissue damage. Furthermore, upon review of the wound site, we found evidence of tendinous injury, suggesting that opting for conservative management would have only delayed the need for future orthopedic surgical intervention.

\section{Conclusions}

This is a unique case of bullet extraction by mechanical removal using entrapped shoe fibers surrounding a lodged bullet. While current recommendations for gunshot wound management involve conservative versus surgical management, we demonstrate a fortuitous situation involving successful and minimally invasive extraction followed by routine antibiotic and outpatient management. 


\section{Additional Information}

\section{Disclosures}

Human subjects: All authors have confirmed that this study did not involve human participants or tissue. Conflicts of interest: In compliance with the ICMJE uniform disclosure form, all authors declare the following: Payment/services info: All authors have declared that no financial support was received from any organization for the submitted work. Financial relationships: All authors have declared that they have no financial relationships at present or within the previous three years with any organizations that might have an interest in the submitted work. Other relationships: All authors have declared that there are no other relationships or activities that could appear to have influenced the submitted work.

\section{References}

1. Firearm violence prevention. (2020). Accessed: April 19, 2021: https://www.cdc.gov/violenceprevention/firearms/index.html.

2. Fowler KA, Dahlberg LL, Haileyesus T, Annest JL: Firearm injuries in the United States . Prev Med. 2015, 79:5-14. 10.1016/j.ypmed.2015.06.002

3. Gonzalez T, Briceno J, Velasco B, Kaiser P, Stenquist D, Miller C, Kwon JY: Gunshot-related injuries to the foot \& ankle: review article. Foot Ankle Int. 2020, 41:486-496. 10.1177/1071100720901712

4. Reginelli A, Russo A, Maresca D, Martiniello C, Cappabianca S, Brunese L: Imaging assessment of gunshot wounds. Semin Ultrasound CT MR. 2015, 36:57-67. 10.1053/j.sult.2014.10.005

5. Riehl JT, Sassoon A, Connolly K, Haidukewych GJ, Koval KJ: Retained bullet removal in civilian pelvis and extremity gunshot injuries: a systematic review. Clin Orthop Relat Res. 2013, 471:3956-3960. 10.1007/s11999-013-3260-8

6. Tosti R, Rehman S: Surgical management principles of gunshot-related fractures. Orthop Clin North Am. 2013, 44:529-540. 10.1016/j.ocl.2013.06.006

7. Woloszyn JT, Uitvlugt GM, Castle ME: Management of civilian gunshot fractures of the extremities . Clin Orthop Relat Res. 1988, 247-251.

8. Maqungo S, Kauta N, Held M, Mazibuko T, Keel MJ, Laubscher M, Ahmad SS: Gunshot injuries to the lower extremities: issues, controversies and algorithm of management. Injury. 2020, 51:1426-1431. 10.1016/j.injury.2020.05.024

9. Omid R, Stone MA, Zalavras CG, Marecek GS: Gunshot wounds to the upper extremity. J Am Acad Orthop Surg. 2019, 27:301-310. 10.5435/JAAOS-D-17-00676 